\title{
Research Paper \\ Image and Value Characteristics of Cranial US for Diagnosis of Meningeal Hemorrhage at Thanh Hoa Hospital of Pediatrics
}

\author{
Nguyen Van Trung* \\ Thanh Hoa Hospital of Pediatrics, Quang Trung 3, Dong Ve, Thanh Hoa, Vietnam \\ Received 22 July 2020 \\ Revised 12 August 2020; Accepted 21 August 2020
}

\begin{abstract}
Purpose: To describe the characteristics of cerebral hemorrhage images using cranial US compared with CT scan.

Methods: A cross-sectional descriptive study was carried out on 36 infants under 28 days of age diagnosed and treated for meningeal hemorrhage at Thanh Hoa Hospital of Pediatrics from August 2013 to August 2015.

Results: The value of cranial US compared with CT scan had the sensitivity, specificity with $68,8 \%$ and $87,5 \%$ respectively, and AUC was 0,781. Kappa index was 0.61. Direct signs of cerebral hemorrhage on ultrasound: Hyperecoic $73.3 \%$, inhomogenous echo $20 \%$, hypoecoic $6.7 \%$. Hematoma size: $40 \%$ less than $1 \mathrm{~cm}, 53.3 \%$ from $1-3 \mathrm{~cm}, 6.7 \%$ above $3 \mathrm{~cm}$. Hemorrhage position in the parenchyma $40 \%$, subarachnoid $33,3 \%$, mixed $26.7 \%$. Indirect signs of hemorrhage level III, IV was $93,3 \%$, level I, II was $6.7 \%$. The midline shift grade I was $60 \%$, grade was II $33.3 \%$ and grade III was $6.7 \%$.
\end{abstract}

Conclusion: Cranial US is valuable for diagnosing cerebral hemorrhage in newborns.

Keywords: meningeal hemorrhage

\footnotetext{
Corresponding author.

E-mail address: trungnv@yahoo.com

https://doi.org/10.25073/jprp.v4i4.222
} 


\title{
Đặc điểm hình ảnh và giá trị của siêu âm qua thóp trong chẩn đoán xuất huyết não màng não tại Bệnh viện Nhi Thanh Hoá
}

\author{
Nguyễn Văn Trung* \\ Bệnh viện Nhi Thanh Hóa, Quang Trung 3, Phwờng Đông Vệ - TP Thanh Hóa, Việt Nam \\ Nhận ngày 22 tháng 7 năm 2020 \\ Chỉnh sửa ngày 12 tháng 8 năm 2020; Chấp nhận đăng ngày 21 tháng 8 năm 2020
}

\section{Tóm tắt}

Mục tiêu: Mô tả đặc điểm hình ảnh xuất huyết não trên siêu âm qua thóp và Giá trị của siêu âm qua thóp trong chẩn đoán xuất huyết não màng não có đối chiếu với chụp CLVT.

Phương pháp: Nghiên cứu mô tả cắt ngang tiến cứu trên 36 trẻ sơ sinh dưới 28 ngày tuổi được chẩn đoán và điều trị xuất huyết não màng não tại Bệnh viện Nhi Thanh Hoá từ tháng 8 năm 2013 đến 8 năm 2015.

Kết quả: Giá trị của Siêu âm qua thóp so với cắt lớp vi tính sọ não có độ nhạy, độ đặc hiệu lần lượt là $68,8 \%$ và $87,5 \%$; và $A U C$ là 0 , chỉ số Kappa 0.61 . Dấu hiệu trực tiếp của xuất huyết não trên siêu âm: Hình ảnh ECHO tăng âm 73,3\%, hỗn hợp âm 20\%, giảm âm 6,7\%. Kích thước khối máu tụ $40 \%$ dưới $1 \mathrm{~cm}, 53,3 \%$ từ $1-3 \mathrm{~cm}, 6,7 \%$ trên $3 \mathrm{~cm}$. Vị trí xuất huyết trong nhu mô 40\%, dưới nhện 33,3\% hỗn hợp 26,7\%. Dấu hiệu gián tiếp mức độ xuất huyết độ III, IV 93,3\% độ I, II 6,7\%. Mức độ đè đẩy đường giữa độ I $60 \%$, độ II 33,3\% và độ III 6,7\%.

Kết luận: Siêu âm qua thóp có giá trị cho chẩn đoán xuất huyết não cho trẻ sơ sinh.

Tì khóa: xuất huyết não màng não

\section{1. Đặt vấn đề}

Xuất huyết não - màng não khá phổ biến ở trẻ sơ sinh và là một trong những nguyên nhân chính gây tử vong và di chứng thần kinh về sau ở trẻ sơ sinh. Theo Malcomlm và cộng sự $70 \%$ trường hợp mổ tử thi sơ sinh có XHNMN ở mức độ khác nhau và xuất huyết não thất hay gặp nhất $[1,2]$. Theo Ninh Thị Ứng, tỷ lệ tử vong của xuất huyết não - màng não ở trẻ sơ sinh là 4,3-6,7\%,

"Tác giả liên hệ.

Địa chỉemail: trungnv@yahoo.com

https://doi.org/10.25073/jprp.v4i4.222 đứng thứ 9 trong số 10 bệnh có tỷ lệ tử vong cao nhất ở trẻ em [3].

Các phương pháp chụp cắt lớp vi tính, cộng hưởng từ cho hình ảnh khách quan, nhưng giá thành cao, không thực hiện cấp cứu tại giường, mặt khác cộng hưởng từ trẻ phải gây mê, còn CLVT sử dụng tia $\mathrm{X}$ ảnh hưởng đến sức khoẻ và sự phát triển của trẻ. Khắc phục một số hạn chế đó siêu âm qua thóp là kỹ thuật không xâm nhập, rẻ tiền, có thể thực hiện tại giường có độ nhạy và đặc hiệu tương đối cao so với CLVT [4-7].

Bệnh viện Nhi Thanh Hóa đã ứng dụng kĩ thuật siêu âm qua thóp chẩn đoán XHNMN từ năm 2008 [8], tuy nhiên chưa 
có nghiên cứu nào đánh giá giá trị của phương pháp này. Chính vì vậy, chúng tôi nghiên cứu đề tài:

Nghiên cứu đặc điểm hình ảnh và giá trị của siêu âm qua thóp trong chẩn đoán XHNMN tại Bệnh viện Nhi Thanh Hoá với 2 mục tiêu:

1. Mô tả đặc điểm hình ảnh xuất huyết não trên siêu âm qua thóp

2. Giá trị của siêu âm qua thóp trong chẩn đoán xuất huyết não màng não có đối chiếu với chụp CLVT.

\section{2. Đối tượng và phương pháp}

\section{1. Đối tượng nghiên cứu}

Trẻ sơ sinh (dưới 28 ngày tuổi) được chẩn đoán và điều trị xuất huyết não màng não tại Bệnh viện Nhi Thanh Hoá từ tháng 8 năm 2013 đến 8 năm 2015.

\subsection{Phưong pháp nghiên cưu} tích

Nghiên cứu mô tả cắt ngang, có phân

\subsection{Cỡ mẫu nghiên cứu}

Chọn toàn bộ cỡ mẫu 36 trẻ sơ sinh chẩn đoán và điều trị xuất huyết não màng não tại Bệnh viện Nhi Thanh Hoá từ tháng 8 năm 2013 đến 8 năm 2015.

\section{Kết quả}

Trong thời gian nghiên cứu có 36 bệnh nhân đủ tiêu chuẩn lựa chọn

\section{1. Đặc điểm hình ảnh SAQT}

3.1.1. Vị trí xuất huyết trên siêu âm và CLCT
Bảng 1. Vị trí xuất huyết trên SAQT và CLVT

\begin{tabular}{|c|c|c|c|}
\hline Kết quả & $\begin{array}{c}\text { SAQT } \\
(\mathrm{n}=15)\end{array}$ & $\begin{array}{c}\text { CLVT }(\mathrm{n}= \\
36)\end{array}$ & $\mathrm{P}$ \\
\hline $\begin{array}{c}\text { XH dưới } \\
\text { nhện }\end{array}$ & $\begin{array}{c}5 \\
(33,3 \%)\end{array}$ & $\begin{array}{c}13 \\
(36,1 \%)\end{array}$ & 0,336 \\
\hline $\begin{array}{c}\text { Xh nhu } \\
\text { mô }\end{array}$ & $6(40 \%)$ & $\begin{array}{c}17 \\
(47,2 \%)\end{array}$ & 0,41 \\
\hline $\begin{array}{c}\text { XH dưới } \\
\text { màng } \\
\text { cứng }\end{array}$ & 0 & $1(2,8 \%)$ & 0,52 \\
\hline $\begin{array}{c}\text { XH hỗn } \\
\text { hợp. }\end{array}$ & $\begin{array}{c}4 \\
(26,7 \%)\end{array}$ & $5(13,9 \%)$ & 0, \\
\hline
\end{tabular}

Nhận xét: Không có sự khác biệt có ý nghĩa thống kê $(\mathrm{p}>0,05)$ về vị trí xuất huyết trên SAQT và CLVT. Có 1 trường hợp $\mathrm{XH}$ dưới màng cứng kết hợp xuất huyết nhu mô quan sát thấy trên CLVT nhưng không thấy trên SAQT.

\subsection{Phân độ xuất huyết não thất trên $S A Q T$}

Bảng 2. Phân độ xuất huyết trên SAQT

\begin{tabular}{|l|l|l|l|l|c|}
\hline $\begin{array}{l}\text { Số } \\
\text { lượng }\end{array}$ & $\begin{array}{l}\text { Độ } \\
\text { I }\end{array}$ & $\begin{array}{l}\text { Độ } \\
\text { II }\end{array}$ & $\begin{array}{l}\text { Độ } \\
\text { III }\end{array}$ & $\begin{array}{l}\text { Độ } \\
\text { IV }\end{array}$ & Tổng \\
\hline $\begin{array}{l}\text { Số } \\
\text { lượng }\end{array}$ & 0 & 1 & 8 & 6 & 15 \\
\hline $\begin{array}{l}\text { Tỷ lệ } \\
(\%)\end{array}$ & 0 & 6,7 & 53,3 & 40 & 100 \\
\hline
\end{tabular}

Nhận xét: Mức độ xuất huyết não thất độ III, IV trên SAQT chiếm tới 93,3\%. Không có $\mathrm{BN}$ độ I và chỉ có 1 bệnh nhân độ II chiếm $6,7 \%$.

\subsection{Hình ảnh khối máu tụ trên SAQT}

Bảng 3. Hình ảnh máu tụ trên SAQT

\begin{tabular}{|c|c|c|c|c|}
\hline $\begin{array}{c}\text { Máu tụ } \\
\text { Số lượng }\end{array}$ & $\begin{array}{c}\text { Tăng } \\
\text { âm }\end{array}$ & $\begin{array}{c}\text { Giảm } \\
\text { âm }\end{array}$ & $\begin{array}{c}\text { Hỗn } \\
\text { hợp âm }\end{array}$ & Tổng \\
\hline Số lượng & 11 & 1 & 3 & 15 \\
\hline Tỷ lệ(\%) & $73,3 \%$ & $6,7 \%$ & $20 \%$ & $100 \%$ \\
\hline
\end{tabular}


Nhận xét: Hình ảnh xuất huyết trên siêu âm chủ yếu tăng âm chiếm 73,3\%, hỗn hợp âm, giảm âm chiếm $20 \%$ và $6,7 \%$.

\subsection{Mức độ đè đẩy đường giữa.}

Bảng 4. Mức độ đè đẩy đường giữa

\begin{tabular}{|l|c|c|c|c|}
\hline $\begin{array}{l}\text { Số Độ } \\
\text { lượng }\end{array}$ & Độ I & Độ II & $\begin{array}{c}\text { Độ } \\
\text { III }\end{array}$ & Tổng \\
\hline Số lượng & 9 & 5 & 1 & 15 \\
\hline Tỷ lệ $(\%)$ & $60 \%$ & $33,3 \%$ & $6,7 \%$ & $100 \%$ \\
\hline
\end{tabular}

Nhận xét: Mức độ đè đẩy đường giữa chủ yếu độ I chiếm $60 \%$, độ II chiếm $33,3 \%$, độ III chỉ gặp 1 bệnh nhân chiếm $6,7 \%$.

\subsection{Kích thước khối máu trên SAQT}

Bảng 5. Kích thước khối máu tụ trên SAQT

\begin{tabular}{|c|c|c|c|c|}
\hline $\begin{array}{c}\text { Kích } \\
\text { thước }\end{array}$ & $<1 \mathrm{~cm}$ & $1-3 \mathrm{~cm}$ & $>3 \mathrm{~cm}$ & Tổng \\
\hline $\begin{array}{c}\text { Số } \\
\text { lượng }\end{array}$ & 6 & 8 & 1 & 15 \\
\hline $\begin{array}{c}\text { Tỷ lệ } \\
(\%)\end{array}$ & $40 \%$ & $53,3 \%$ & $6,7 \%$ & $100 \%$ \\
\hline
\end{tabular}

Nhận xét: SAQT thấy 53,3\% BN khối máu tụ kích thước từ $1-3 \mathrm{~cm}, 40 \%$ kích thước $<1 \mathrm{~cm}$. có 1 bệnh nhân kích thước $>3 \mathrm{~cm}$.

3.6. Giá trị của siêu âm qua thóp trong chẩn đoán xuất huyết não màng não có đối chiếu với chup CLVT

Bảng 6. Đối chiếu SAQT với CLVT

\begin{tabular}{|l|c|c|c|}
\hline \multicolumn{1}{|c|}{ CLVT } & Có & Không & Tổng \\
\hline Có & & & \\
\hline Không & 33 & 15 & 48 \\
\hline Tồng & 36 & 36 & 72 \\
\hline
\end{tabular}

Nhận xét: Chỉ số Kappa: $\mathrm{k}=0,61$ hai phương pháp có mức độ phù hợp cao. : độ nhạy 68,8\% (95\%CI 53,7-81,3), độ đặc hiệu $87,5 \%$ (95\%CI 67,6-97,3), diện tích dưới ROC (AUC) là 0,781

\section{Bàn luận}

\section{1. Đặc điểm hình ảnh SAQT.}

4.1.1. Vị trí xuất huyết trên SAQT và CLVT.

Nghiên cứu của chúng tôi trong số 36 trẻ XHNMN có 15 trẻ phát hiện trên SAQT và 36 trẻ phát hiện trên CLVT. Vị trí xuất huyết bao gồm dưới nhện, trong nhu mô và hô̂n hợp cả trong nhu mô lẫn dưới nhện, trong não thất. Qua bảng 2 thấy không có sự khác biệt có ý nghĩa thống kê về vị trí xuất huyết não giữa siêu âm qua thóp và CLVT. Điều này có thể lý giải được bởi vì những bệnh nhân XHNMN siêu âm phát hiện chủ yếu kích thước nằm trong khoảng $1-3 \mathrm{~cm}$, mặt khác trẻ sơ sinh bản sọ mỏng, khoang dưới nhện rộng dễ lách đầu dò khảo sát. Tuy nhiên một nhược điểm lớn của SAQT đó là phụ thuộc rất nhiều vào chủ quan của người làm cho nên độ chính xác không cao và không đồng đều. Yếu tố khách quan nữa là những phần cầu trúc sâu như vùng tiểu não, bể đáy rất khó để tia siêu âm đi qua, cộng thêm trẻ XHNMN thường nằm lồng âp, thở mày ảnh hưởng tới kỹ thuật siêu âm. Quan điểm này phù hợp với nghiên cứu của tác giả Thu Phương - Ninh Thị Úng [8].

4.1.2. Phân độ xuất huyết trên SAQT

Theo bảng 2, mức độ xuất huyết trên siêu âm qua thóp chủ yếu là độ III, IV chiếm 93,3\%, 1 bệnh nhân độ II chiếm $6,7 \%$ không có bệnh nhân nào độ I. Theo phân loại của Papile xuất huyết độ I, II không gây giãn não thất và lâm sàng hầu như không có biểu hiện mất máu rõ. Chỉ khi xuất huyết độ III, IV thì mới có máu trong não thất gây giãn não thất (độ III) và kèm theo máu tụ trong nhu mô não (IV).

4.1.3. Hình ảnh máu tụ trên SAQT 
Theo bảng 3 SAQT xác định 73,3\% xuất huyết não biểu hiện tăng âm hơn so với chất xám nhu mô não. Điều này cho thấy tính chất chảy máu cấp tính của tổn thương. Bởi vì khi chảy máu cấp tính các tế bào hồng cầu, bạch cầu, tiểu cầu vỡ thoát ra ngoài lòng mạch tập trung thành đám, khi tia siêu âm đâm xuyên qua sẽ gây hiện tượng phản hồi âm mạnh tức là tăng âm hơn so với nhu mô chất xám. Còn trong trường hợp khi máu chảy đã có hiện tượng thoái hóa hồng cầu, giáng hóa hemoglobin dịch hóa các huyết tương lúc này sẽ gây hiện tượng giảm âm. Trong trường hợp chảy máu bán cấp gây hình ảnh hỗn hợp âm. Trong nghiên cứu có 3 trường hợp chiếm $20 \%$ hình ảnh siêu âm là hỗn hợp âm.

\subsubsection{Kích thước khối máu tụ.}

Theo bảng 5 cho thấy $53,3 \%$ khối máu tụ kích thước từ $1-3 \mathrm{~cm}, 40 \%$ khối máu tụ có kích thước $<1 \mathrm{~cm}$, có 1 bệnh nhân kích thước $>3 \mathrm{~cm}$.

Kích thước khối máu tụ càng cao sẽ gây hiệu ứng tổ chức nhu mô não và hệ thống não thất càng lớn. Do đó cho nên tỷ lệ trẻ mức độ XHNMN có kích thước khối máu tụ $<3 \mathrm{~cm}$ chiếm tới 93,3 \%, chỉ có 1 bệnh nhận xuất huyết lớn $>3 \mathrm{~cm}$ hiệu ứng khối mạnh và nhanh chóng nguy kịch dẫn tới tử vong. Như vậy thông tin về kích thước khối máu tụ góp phần quan trong giúp tiên lượng mức độ nguy kịch của bệnh nhân.

\subsubsection{Mức độ đè đẩy đường giữa.}

Mức độ đè đẩy đường giữa 93,3\% độ $\mathrm{I}$, II tức là mức độ đường giữa bị đầy sang bên đối diện di lệch từ 5-10mm, có 1 bệnh nhân có dầu hiệu đè đẩy đường giữa độ III. Dầu hiệu này phụ thuộc vào kích thước của khối xuất huyết, khi khối máu tụ càng lớn thì hiệu ứng khối lên đường giữa càng nhiều. Khi nhiều tổn thương kết hợp vưa xuất huyết trong nhu mô vừa xuất huyết dưới nhện thì mức độ mất máu càng nhiều và hiệu ứng khối càng lớn. Trong nghiên cứu 1 bệnh nhân xuât huyết trong nhu mô não kích thước $>3 \mathrm{~cm}$ kết hợp xuất huyết dưới màng cứng do đó gây hiệu ứng khối đè đẩy đường giữa độ III. Như vậy dấu hiệu này cũng có giá trị tiên lượng mức độ nguy kịch cho bệnh nhân. Về mặt thực tiễn khi siêu âm khi phát hiện dấu hiệu gián tiếp đè đẩy đường giữa, dù không quan sát được khối máu tụ hay nguyên nhân choán chỗ nào khác, các bác sỹ lâm sàng cũng phải cảnh giác với tổn thương sâu và chỉ định kỹ thuật cao hơn, vì tổn thương có thể ở sâu trong nhu mô mà tia siêu âm không khảo sát được.

4.2. Giá trị của siêu âm qua thóp trong chẩn đoán xuất huyết não màng não có đối chiếu với chụp CLVT

Theo bảng 6 cho thấy chỉ số Kappa của hai phương pháp SAQT và CLVT sọ não là 0,61 cho thấy có độ phù hợp cao,

Độ nhạy 68,8\% (95\%CI 53,7-81,3), độ đặc hiệu 87,5 \% (95\%CI 67,6-97,3), diện tích dưới ROC (AUC) là 0,781 .

Độ nhạy, độ đặc hiệu và độ chính xác của SAQT so với CLVT lần lượt là $41,6 \%$; $88.9 \%$ và $65,4 \%$. Nghiên cứu của chúng tôi phù hợp với tác giả Ninh Thị Úng [8]. Tác giả này nghiên cứu thấy độ nhạy của $\mathrm{SAQT}$ 30- 40\%. Tỷ lệ của chúng tôi cao hơn bởi vì đối tượng lựa chọn có khác, tất cả các đối tượng lựa chọn của chúng tôi đều phải có cả SAQT và CLVT. Mặt khác nghiên cứu của tác giả Ninh Thi Úng và cộng sự tiến hành từ năm 1993 khi đó siêu âm còn khá ít chất lượng hình ảnh chưa cao, mà siêu âm lại phụ thuốc rất nhiều vào chủ quan người làm.

\section{Kết luận}

Qua nghiên cứu 36 bệnh nhân XHNMN tại Bệnh viện Nhi Thanh Hóa từ 8/20138/2015 chúng tôi nhận thấy:

\subsection{Về đặc điểm hình ảnh của $S A Q T$}


- Các dấu hiệu trực tiếp:

+ Kích thước khối máu tụ có $40 \%$ dưới $1 \mathrm{~cm}, 53,3 \% 1-3 \mathrm{~cm}, 6,7 \%$ kích thước trên $3 \mathrm{~cm}$.

+ Vị trí xuất huyết: Trong nhu mô $40 \%$, dưới nhện 33,3\%, hỗn hợp 26,7\%. Không có sự khác biệt có ý nghĩa thống kê $(\mathrm{p}>0,05)$ về vị trí xuất huyết so với CLVT.

+ Hình ảnh trên SAQT: tăng âm chiếm $73,3 \%$, hỗn hợp âm 20\% giảm âm 6,7\%.

- Các dấu hiệu gián tiếp:

+ Mức độ xuất huyết não thất: độ III, IV chiếm 93,3\%, độ I,II chiếm 6,7\%.

+ Mức độ đè đẩy đường giữa: độ I $60 \%$; độ II 33,3\%; độ III 6,7\%.

\subsection{Giá trị của SAQT trong chẩn đoán XHNMN}

Đối chiếu với CLVT sọ não kết quả nghiên cứu như sau: Chỉ số Kappa 0,61 (hai phương pháp có mức độ phù hợp cao). Độ nhạy độ nhạy 68,8\% (95\%CI 53,7-81,3), độ đặc hiệu 87,5 \% (95\%CI 67,6-97,3), diện tích dưới ROC là 0,781 .

\section{Tài liệu tham khảo}

[1] Chuong N. Anatomical features of brain spinal function applied to neurological practice. Journal of Neurology 2005;8:68. (in Vietnamese)

[2] Huy NQ. Human Brain Anatomy. Hanoi Publishing House; 2006 (in Vietnamese)

[3] Ung NT, Phuong LT. Initial brain ultrasound application in children with cerebral heamorrhage. Journal of Pediatrics 1993:141146. (in Vietnamese)

[4] Kinh D. Human Embryology. Medical Publishing House; 2002:277-295. (in Vietnamese)

[5] Ha NTT. Research on some epidemiological factors and clinical and subclinical characteristics of neonatal meningeal heamorrhage. Master thesis - Hanoi Medical University; 2001. (in Vietnamese)

[6] Hau PV. Research on brain morphology characteristics and anterior cerebral artery doppler index in neurotypical newborns by using transcranial ultrasound. Master of Medicine thesis - Hanoi Medical University; 2012. (in Vietnamese)

[7] Nga VTT. Describing some risk factors for meningeal heamorrhage in premature babies at the National Hospital of Pediatrics. Master thesis - Hanoi Medical University; 2008. (in Vietnamese)

[8] Quyen NQ. Atlas of human anatomy: Head, face and neck. Medical Publishing House; 2003. (in Vietnamese) 